Research Article

\title{
Prediction of Compressive Strength of Geopolymer Concrete Based on Support Vector Machine and Modified Cuckoo Algorithm
}

\author{
Daming Zhang $\mathbb{D}^{1},{ }^{1,2}$ Fangjin Sun $\mathbb{D}^{3},{ }^{3,4,5}$ and Tiantian Liu $\mathbb{i}^{6}$ \\ ${ }^{1}$ Guangxi Key Laboratory of Embedded Technology and Intelligence, Guilin 541006, China \\ ${ }^{2}$ College of Information Science and Engineering, Guilin University of Technology, Guilin 541006, China \\ ${ }^{3}$ Guangxi Key Laboratory of New Energy and Building Energy Saving, Guilin 541004, China \\ ${ }^{4}$ Guangxi Key Laboratory of Geomechanics and Geotechnical Engineering, Guilin University of Technology, Guilin 541004, China \\ ${ }^{5}$ College of Civil Engineering and Architecture, Guilin University of Technology, Guilin 541004, China \\ ${ }^{6}$ College of Civil Engineering, Liaoning Technical University, Fuxin 123000, China
}

Correspondence should be addressed to Fangjin Sun; e_dm@163.com

Received 7 July 2021; Revised 15 September 2021; Accepted 17 September 2021; Published 26 September 2021

Academic Editor: Shengwen Tang

Copyright (C) 2021 Daming Zhang et al. This is an open access article distributed under the Creative Commons Attribution License, which permits unrestricted use, distribution, and reproduction in any medium, provided the original work is properly cited.

Coal gangue-based geopolymer concrete is an environmentally friendly material made from coal gangue, solid waste from the coal mine. Compressive strength is one of the most important indexes for concretes. Different oxide contents of coal gangue will affect the compressive strength of the geopolymer concrete directly. However, there is little study on the relationship between oxide contents and compressive strength of the geopolymer concrete. Experiments are commonly used methods of determining the compressive strength of concretes, including geopolymer concrete, which is time-consuming and inefficient. Therefore, in the work here, a support vector machine and a modified cuckoo algorithm are utilized to predict the compressive strength of geopolymer concrete. An orthogonal factor is introduced to modify the traditional cuckoo algorithm to update new species and accelerate computation convergence. Then, the modified cuckoo algorithm is employed to optimize the parameters in the support vector machine model. Then, the compressive strength predictive model of coal gangue-based geopolymer concrete is established with oxide content of raw materials as the input and compressive strength as the output of the model. The compressive strength of coal gangue-based geopolymer concrete is predicted with different oxide contents in raw materials, and the effects of different oxide contents and oxide combinations on compressive strength are studied and analyzed. The results show that the support vector machine and the modified cuckoo algorithm are valid and accurate in predicting the compressive strength of geopolymer concrete. And, coal gangue geopolymer concrete compressive strength is significantly affected by oxide contents.

\section{Introduction}

In order to overcome the shortcomings of high energy consumption and heavy pollution of traditional concrete, the authors have successfully made coal gangue-based geopolymer by mixing coal gangue, fly ash, and standard sand $[1,2]$. Compressive strength is a very important indicator for evaluating the performance of geopolymer concrete. Many factors affect the compressive strength of coal gangue-based geopolymer concrete. Wang et al. [3] proved that PS concretes have comparable compressive strengths with PC ones at 180 days. Sheng et al. [4] discussed the effect of calcium carbonate hydrate on the mechanical properties of cement-based materials. Fan Bo et al. [5] demonstrated the accuracy of the support vector machine model for accident risk prediction under Gaussian Kernel: the accuracy rate is $73.20 \%$, and the classification of normal traffic flow is $91.44 \%$. Jianbin $\mathrm{Li}$ et al. [6] verified the effectiveness of establishing TBM construction control parameters based on Support Vector Regression. Wang et al. [7] used 29Si MAS NMR and microhardness to study the $\mathrm{C}-\mathrm{S}-\mathrm{H}$ microstructure and micromechanics of cement paste 
under NH4NO3 dissolution. Khatib Zada Farhan et al. [8] assessed important parameters involved in geopolymer materials. Raw materials such as coal gangue and fly ash contain oxides with different compositions and contents. Since the polymer process of geopolymers is the dissolving of $\mathrm{Al}$ and $\mathrm{Si}$ elements in the raw materials in an alkaline environment, and finally forming Al-O-Si and Si-O-Si crystals [9], the oxide composition and its content in raw materials will have an important impact on the compressive strength of the geopolymer concrete. At present, the most commonly used method for determining the compressive strength of concrete tests, which is early curing, is long (usually 28 days for maintenance) and a lot of manpower, material, and financial resources are needed. Therefore, finding an intelligent algorithm to replace part of the test content can predict the compressive strength of geopolymer concrete as soon as possible after pouring, which can reduce the consumption of manpower, material resources, financial resources, and time, which is of great theoretical value and practical significance for improving the progress and quality of construction. In fact, the prediction of compressive strength of cement and other cementitious materials and concrete has also received the attention of relevant researchers in recent years. But the artificial neural network prediction method also has obvious problems, artificial neural network learning algorithm has good function approximation ability and self-learning ability, but it is based on the theory of large sample and minimum empirical risk, and these shortcomings limit its application to some extent. Therefore, it is of great importance to study appropriate intelligent algorithms to predict the compressive strength and reveal the effects of different oxide contents on the compressive strength of coal gangue-based geopolymer concrete.

Support Vector Machine (SVM for short) is a new model based on statistical theory, which shows many advantages and superiority in solving small sample, highly nonlinear, and high-dimensional pattern recognition problems. There are still problems to be solved in the support vector machine, and how to optimize the kernel function which is suitable for the given problem is a difficult problem to be studied in depth. This paper uses an intelligent cuckoo algorithm to optimize the kernel function and related parameters in the support vector machine. In order to overcome the shortcomings of the traditional cuckoo algorithm, such as large search range and low search efficiency, this paper proposes to introduce the orthogonal crossover operator into the traditional cuckoo algorithm to obtain the improved cuckoo algorithm to quickly find the optimal solution.

In this paper, the compressive strength of coal ganguebased geopolymer concrete is predicted based on a support vector machine and improved cuckoo algorithm. An orthogonal crossover operator is introduced to improve the traditional cuckoo algorithm, and then the improved cuckoo algorithm is used to optimize the parameters of the support vector machine. The prediction model and algorithm of compressive strength of coal gangue-based geopolymer concrete are established. In the prediction model of compressive strength, the important factors that affect the compressive strength of geopolymer concrete based on coal gangue are discussed. The oxide content in raw materials is used as the input parameter; the compressive strength of coal gangue-based geopolymer concrete is used as the output parameter. The prediction model between the compressive strength of coal gangue-based geopolymer concrete and the oxide content of raw materials was established. The existing data are used to train the prediction model; after meeting the accuracy requirements, the compressive strength of coal gangue-based geopolymer concrete with different oxide content in raw materials and oxide combination is predicted. The influence of oxide content on the compressive strength of coal gangue-based geopolymer concrete is studied and analyzed.

\section{Preparation of Coal Gangue-Based Geopolymer Concrete}

In this paper, coal gangue-based geopolymer concrete has been successfully made using coal gangue, fly ash, and sand as raw materials. The coal gangue selected in this paper is from spontaneous combustion coal gangue in Fuxin City, Liaoning Province. The main chemical components of Fuxin spontaneous combustion coal gangue are $\mathrm{SiO}_{2}, \mathrm{Al}_{2} \mathrm{O}_{3}$, $\mathrm{Fe}_{2} \mathrm{O}_{3}, \mathrm{CaO}$, and other elements. The main chemical constituents of coal gangue are shown in Table 1 [10]. The main chemical components of fly ash are shown in Table 2 . Technical indicators of standard sand are shown in Table 3.

It can be seen from Table 1 that the main chemical compositions of coal gangue after spontaneous combustion will not change significantly, $\mathrm{SiO}_{2}$ and $\mathrm{Al}_{2} \mathrm{O}_{3}$ are still the main components, and the content of $\mathrm{SiO}_{2}$ slightly increases.

The main equipment used in the test includes a jaw crusher, sealed sample preparation crusher, desktop electric drying box, standard constant temperature, and humidity curing box, universal testing machine, etc. In order to study the influence of curing temperature on the compressive strength of geopolymer concrete, four of the test blocks are cured in the natural room temperature environment (20-25 ${ }^{\circ} \mathrm{C}$ ), and the other four specimens are bonded with plastic film as a group of curing in the oven. In order to compare the effects of different curing temperatures on the performance of geopolymer concrete, different curing temperatures are used in the oven. After curing different ages (3d, $7 d, 28 d$ ), the compressive strength and flexural strength of all specimens were tested after $1 \mathrm{~d}$ in the room. The final compressive strength and flexural strength were taken as the average value of the same group.

The process of making geopolymer concrete test blocks is as follows:

(1) Firstly, sodium hydroxide (SH) solution was mixed with calcium carbonate (CC) powder to generate alkaline excitation powder composed of calcium hydroxide $(\mathrm{CH})$, sodium carbonate $(\mathrm{SC})$, and pirssonite $(\mathrm{P})$, which was dried in an oven at $80^{\circ}$ for 8 hours.

(2) Then, it was crushed to fixed particle size, and finally the activator powder particle size of less than 
TABLE 1: Analysis results of main chemical components of coal gangue $(\%)$.

\begin{tabular}{lc}
\hline Composition & Content (\%) \\
\hline $\mathrm{SiO}_{2}$ & 65.09 \\
$\mathrm{Al}_{2} \mathrm{O}_{3}$ & 16.86 \\
$\mathrm{~K}_{2} \mathrm{O}$ & 2.67 \\
$\mathrm{CaO}$ & 2.07 \\
$\mathrm{MgO}$ & 1.98 \\
$\mathrm{Fe}_{2} \mathrm{O}_{3}$ & 6.15 \\
$\mathrm{Na}_{2} \mathrm{O}$ & 1.64 \\
$\mathrm{TiO}=$ & 0.74 \\
$\mathrm{~S}$ & 0.53 \\
Loss on ignition & 1.49 \\
\hline
\end{tabular}

TABle 2: Main chemical components of fly ash (\%).

\begin{tabular}{lc}
\hline Compositions & Contents (\%) \\
\hline $\mathrm{SiO}_{2}$ & 62.02 \\
$\mathrm{Al}_{2} \mathrm{O}_{3}$ & 11.29 \\
$\mathrm{CaO}$ & 6.07 \\
$\mathrm{~K}_{2} \mathrm{O}$ & 1.63 \\
$\mathrm{Na}{ }_{2} \mathrm{O}$ & 0.13 \\
$\mathrm{MgO}$ & 1.56 \\
$\mathrm{Fe}_{2} \mathrm{O}_{3}$ & 5.19 \\
$\mathrm{TiO}_{2}$ & 1.00 \\
$\mathrm{SO}_{3}$ & 1.04 \\
\hline
\end{tabular}

TABle 3: Technical indicators of standard sand.

\begin{tabular}{lc}
\hline \multicolumn{2}{c}{ Particle sizes range } \\
Size of screen mesh $(\mathrm{mm})$ & Cumulative sieve residue $(\%)$ \\
\hline 2.0 & 0 \\
1.6 & 7 \\
1.0 & 33 \\
0.5 & 67 \\
0.16 & 87 \\
0.08 & 99 \\
\hline
\end{tabular}

$0.03 \mathrm{~mm}$ powder was taken, as an activator for the preparation of coal gangue based geopolymer concrete.

(3) Then, the (spontaneous combustion) coal gangue block is crushed by a sledgehammer and repeatedly crushed into small particles in a crusher and sieved to obtain a powder with a particle size of $0.01-0.09 \mathrm{~mm}$.

(4) Sands and stones were poured into the mixer, with stirring for about 140s, then the coal gangue powder and fly ash were poured, with stirring for about 20s, and finally the dry powder activator powder was added, with stirring for about 120 s.

(5) After the final mixing is completed, the geopolymer concrete is poured into the mold, vibrated and compacted, and finally smoothed to make the geopolymer concrete test blocks.
The process and the specimens are shown in Figure 1 [10].

2.1. The Theory of Support Vector Machine. The support vector machine model can be expressed for [11]

$$
\begin{gathered}
\min _{w, \xi, \alpha} \quad \frac{1}{2}\|w\|^{2}+C \sum_{i=1}\left(\xi_{i}+\xi_{i}^{*}\right), \\
f(x)-y_{i} \leq \varepsilon+\xi_{i}, \\
\quad y_{i}-f(x) \leq \varepsilon+\xi_{i}^{*}, \\
\text { s.t. } \quad \xi_{i}, \xi_{i}^{*} \geq 0, \\
\quad i=1,2, \ldots, l .
\end{gathered}
$$

Among them, $\left\{x_{i}, y_{i}\right\}, i=1,2, \ldots, l$ are training samples, $x_{i} \in R^{d}$ is a $d$-dimensional of samples input, and $y_{i} \in R^{c}$ is a $c$-dimensional of samples' output. $f(x)=(\omega * x)+b$, where $\omega$ and $b$ are weight factor and deviation, respectively. $\xi_{i}, \xi_{i} \geq 0$ is relaxation coefficient. $C>0$ is penalty coefficient, which is used to coordinate the gliding property of the fitting error and the fitting function.

The optimization of the above support vector machine can be achieved by $K\left(x_{i}, x_{j}\right)=\left\langle\varphi\left(x_{i}\right), \varphi\left(x_{j}\right)\right\rangle$; this can effectively avoid complex inner product operations in highdimensional space calculations. The mode structure can be written as

$$
\begin{aligned}
& f(x)=\sum_{i=1}^{l}\left(\alpha_{i}-\alpha_{i}^{*}\right) K\left(x_{i}, x_{j}\right)+b, \\
& \text { s.t. } \quad 0 \leq \alpha_{i}, \alpha_{i}^{*} \leq C, \\
& \quad i=1,2, \ldots, l .
\end{aligned}
$$

Among them, the deviation $b$ can be obtained from the support vector obtained for solving. According to the above formula, the value of $\alpha_{i}, \alpha_{i}^{*}$ can be solved; among them, when $\alpha_{i}, \alpha_{i}^{*}$ are nonzero, the corresponding sample is called the amount of support. The specific form depends on the type of kernel function; this paper uses the RBF kernel function to study SVM.

RBF kernel function is for

$$
K\left(x_{i}, x_{j}\right)=\exp \left(\frac{-\left\|x_{i}-x_{j}\right\|^{2}}{2 \sigma^{2}}\right),
$$

where $\sigma$ is nuclear bandwidth.

Then the determination of kernel function is mainly the determination of penalty coefficient $\mathrm{C}$ and the nuclear bandwidth $\sigma$. The value of parameter $\mathrm{C}$ is related to the tolerance error, a larger value of $\mathrm{C}$ allows a smaller error, and a smaller value of $\mathrm{C}$ allows a larger error. In order to select the appropriate parameter $\mathrm{C}$ and nuclear bandwidth $\sigma$, this 


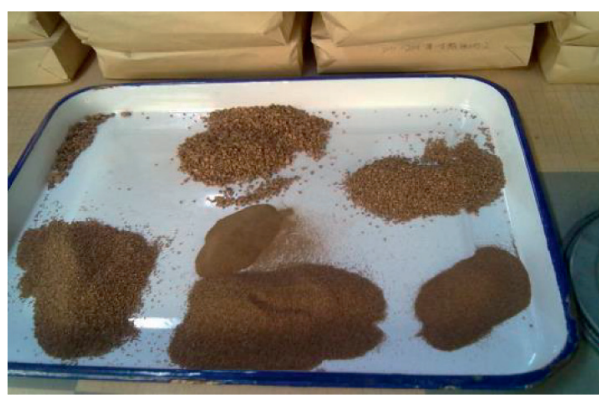

(a)

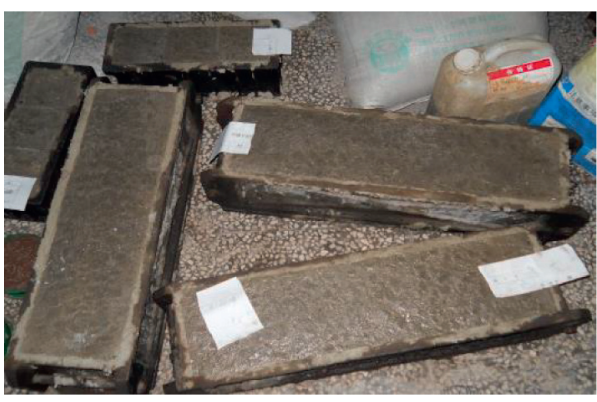

(b)

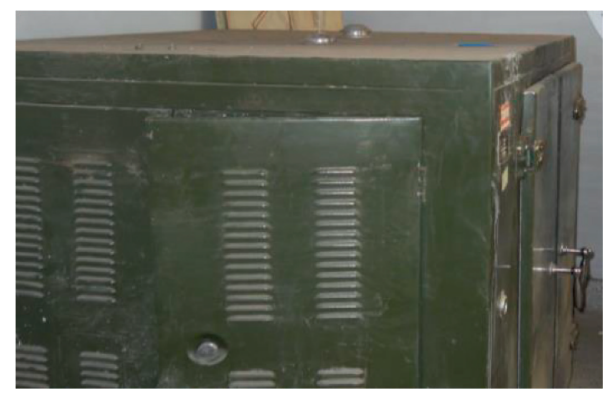

(c)

Figure 1: Process of making geopolymer concrete. (a) Raw materials for experiment. (b) Coal gangue-based geopolymer concrete. (c) Curing.

paper will use the improved cuckoo search algorithm to optimize the $\mathrm{C}$ and $\sigma$, so as to better optimize the support vector machine classification and obtain the optimal $\mathrm{C}$ and $\sigma$.

\subsection{Joint Parameter Optimization Based on Improved Cuckoo Algorithm and Support Vector Machine}

2.2.1. Theoretical Basis of Traditional Cuckoo Algorithm. Firstly, a brief introduction to Lévy flight: Lévy flight is a typical random mechanism of migration, which represents a kind of non-Gaussian random process and is related to the stable distribution of Lévy. It was originally proposed by Paul Pierre Lévy, a French mathematician. The Lévy stable distribution is expressed by scale $\sigma$, characteristic index $\alpha$, displacement $\mu$, and skewness coefficient $\beta$. The continuous Fourier transform of its characteristic function $\phi(t)$ can be used to define the Lévy distribution [12]:

$$
\begin{aligned}
p_{\alpha, \beta}(k ; \mu, \sigma) & =F\left\{p_{\alpha, \beta}(x ; \mu, \sigma)\right\} \equiv \int_{-\infty}^{\infty} \mathrm{d} x e^{i, k, x} P_{\alpha, \beta}(X ; \mu, \sigma) \\
& =\exp \left[i u k-\sigma_{\alpha}|k|^{\alpha}\left(1-i \beta \frac{k}{|k|}\right) \bowtie(k, \alpha)\right] .
\end{aligned}
$$

Among them, $\omega(k, \alpha)=\tan \pi \alpha / 2$, if $\alpha \neq 1,0<\alpha<2$.

Lévy is stable distribution of probability density function, $P_{\alpha, \beta}(x)$ has no unified form, and in three special cases, $P_{\alpha, \beta}(x)$ can be expressed by the following basic function:

(1) Gaussian Distribution: when $\alpha=2$,

$$
\operatorname{Lévy}(\lambda) \sim \mathrm{u}=\mathrm{t}^{-\lambda}, \quad(1<\lambda<3) .
$$

On account of $\tan \pi=0$, in the system of Gaussian distribution $\beta$ with it is independent.

(2) Cauchy Distribution: when $\alpha=1, \beta=0$,

$$
p_{1,0}(x)=\frac{1}{\pi\left(1+x^{2}\right)} .
$$

(3) Lévy Distribution: when $\alpha=1 / 2, \beta=1$,

$$
\begin{aligned}
& P_{(1 / 2), 1}(x)=\frac{1}{\sqrt{2} \pi} x^{(-3 / 2)} \exp (-1 / 2 x), \quad x \geq 0, \\
& P_{(1 / 2), 1}(x)=0, \quad x<0 .
\end{aligned}
$$

The probability density function $\lambda(x)$ of jumping step size distribution of Lévy flight decays as follows:

$$
\lambda(x) \approx|x|^{-1-\alpha}, \quad 0<\alpha<2 .
$$

Then the traditional cuckoo algorithm is that, for any given initial population $\mathrm{N}$, the control variable $x$ of the optimization problem is generated and initialized between the maximum and minimum limits,

$$
x_{j, i}^{t}=x_{j, \min }+R_{i, j} \cdot\left(x_{j, \max }-x_{j, \min }\right),
$$

where $j$ represents the control variable of the $i$-th population in the $t$-th iteration, where $R_{i, j} \in[0,1]$ is a uniformly distributed random number.

When the cuckoo $i$ produces a new solution $x_{t+1}$, a Lévy flight is performed: 


$$
x_{i}^{t+1}=x_{i}^{t}+\alpha \oplus L(\lambda) .
$$

The formula shows that the current position (the first term in the formula) and the transition probability (the second term in the formula) jointly determine the position of the next iteration. In the formula, $\alpha>0$ represents the step size of the control variable, in which $\oplus$ represents point-topoint multiplication. $L(\lambda)$ represents the path of random search.

Lévy operator can be written as

$$
\operatorname{Levy}(\lambda)=\left|\frac{\Gamma(1+\lambda) \times \sin (\pi \times \lambda / 2)}{\Gamma(1+\lambda / 2) \times \lambda \times 2^{(\lambda-1 / 2)}}\right| .
$$

Among them, $\lambda$ is the distribution coefficient, and $0.3<\lambda \leq 1.99 \Gamma(\bullet)$ is the Gammer distribution function.

Then the $i$ th population at the $(t+1)$ th iteration can be expressed as

$$
x_{i}^{t+1}=x_{i}^{t}+S_{j, i} \times \alpha \oplus L(\lambda) .
$$

Among them, $S_{j, i}=\left(x_{j, i}^{t}-x_{\text {best }}^{t}\right)$ is a step size adjustment coefficient, $j=1,2, \ldots, m$ is total of control variable, $i=1,2, \ldots, N, x_{\text {best }}^{t}$ is the global optimal solution for the $\mathrm{t}$-th iteration. The step length is $\alpha$, according to the scale of the problem, and $\alpha>0$; in most cases, we can take $\alpha=1$. $\oplus$ represents the multiplication operator.

2.2.2. Modified Cuckoo Search Algorithm. The traditional cuckoo algorithm is introduced above. It can be seen that the Lévy flight operator in the traditional cuckoo algorithm can control the search of the solution, but it usually has search diversity; that is, the search range is large, which will reduce the search efficiency. Only more iteration steps can get the final optimal solution. To improve the searchability of the cuckoo algorithm, speed up the search speed, and quickly find the optimal solution, this paper will introduce an orthogonal crossover operator to the traditional cuckoo algorithm, to update the new population and accelerate the calculation convergence.

Consider a system whose cost depends on $K$ factor, and each factor can take one of the $Q$ levels. To find out the optimal level of each factor and minimize the system cost, if the $K$ and $Q$ are small, each factor level combination can do an experiment, and then you can select the best one. The number of all $Q^{k}$ combinations is $K$. Therefore, in the case that $Q$ and $Q$ are large, it is impossible or ineffective to test all combinations. The test design method can be used to test a representative combination of a small number of samples. Orthogonal design is one of several very popular experimental design tools. It provides a series of orthogonal arrays to accommodate different numbers of factors and different levels. Orthogonal arrays of Quality Factors $Q$ and $M$ combined with $\mathrm{K}$-factors are often expressed as $L_{M}\left(Q^{K}\right)$. For example, $L_{9}\left(3^{4}\right)$ can be expressed as

$$
L_{9}\left(3^{4}\right)=\left[\begin{array}{l}
1111 \\
1222 \\
1333 \\
2123 \\
2231 \\
2312 \\
3132 \\
3213 \\
3321
\end{array}\right] .
$$

Each row in this array represents a combination of levels, that is, an experiment. For example, the last line represents an experiment in which factor 1 is at level 3 , factor 2 is at level 3, factor 3 is at level 2, and factor 4 is at level 1 . Based on this array, we can conduct 9 trials to estimate a good combination of factor levels.

The orthogonality of an orthogonal array means that, in each column, each layer of the element occurs the same number of times, and the possible level combination of any two given factors in the array occurs the same number of times.

This section is based on the theory of orthogonal crossover and introduces the orthogonal crossover (OC) operator to modify the traditional cuckoo algorithm and derive the revised formula. The main idea of the orthogonal crossover (OC) operator is that each attempt to solve the search algorithm can be regarded as an experiment and the genetic operator (crossover and mutation, etc.) is defined as a representative of the upper solution from a sample of multiple representatives, point procedure; therefore, orthogonal design or any other experimental design tool can make genetic operators more statistically significant. Leung and Wang [13] introduce the quantization technique to OC and propose a new version of OC, which we call NOC, to deal with numerical optimization. In this article, we will use NOC in our algorithm.

Based on $L_{M}\left(N^{K}\right)$ to explain the working process of NOC: given two upper-level solutions $e=\left(e_{1}, \ldots, e_{D}\right)$ and $g=\left(g_{1}, \ldots, g_{D}\right) . e$ and $g$ determine variable $x_{i}$ to ensure the minimum searching range $\left(e_{i}, g_{i}\right)$ and the maximum searching range $\left(e_{i}, g_{i}\right)$. NOX first quantifies the searching range in order $x_{i}$ to define the $N$ level: $l_{i 1}, l_{i 2}, l_{i N}$ as follows:

$$
l_{i, j}=\min \left(e_{i}, g_{i}\right)+\frac{j-1}{N-1} \cdot\left(\max \left(e_{i}, g_{i}\right)-\min \left(e_{i}, g_{i}\right)\right), \quad j=1, \ldots N
$$

The search space defined by $e$ and $g$ will have $N^{D}$ points after quantization because each factor has $\mathrm{N}$ possible ones. Suppose we have two parents $e=(1.0,3.0)$ and $g=(3.0,1.0)$ in the two-dimensional search space; this search space is defined by two parents $[1.0,3.0] \times[10,3.0]$. If $Q=3$, after quantization, this search space will contain $Q^{D}=$ $3^{2}=9$ points, because each factor is quantized into three layers. 
Because $D$ is usually much larger than $\mathrm{K}$, it cannot be directly applied to $L_{M}\left(Q^{K}\right)$. To overcome this difficulty, QOC divides $\left(x_{1}, \ldots, x_{D}\right)$ into $K$ subvectors like other OC factors:

$$
\left\{\begin{aligned}
H_{1}^{*}= & \left(x_{1}, \ldots, x_{t 1}\right), \\
\vec{H}_{1}= & \left(x_{t 1+1}, \ldots, x_{t 2}\right), \\
& \longrightarrow \\
\vec{H}_{1}= & \left(x_{t_{x-1}+1}, \ldots, x_{D}\right) .
\end{aligned}\right.
$$

In here, integers of $t_{1}, t_{2}, \ldots, t_{K-1}$ are randomly generated, such as $1<t_{1}<t_{2}<\cdots<t_{K-1}<D$, and QOC treats each $H_{i}$ as a factor and defines the following $Q$ level for $H_{i}$ :

$$
\left\{\begin{array}{c}
\overrightarrow{L_{i 1}}=\left(l_{i_{l-1}+1,1}, l_{i_{l-1}+2,1}, \ldots, l_{i_{l}, 1}\right), \\
\overrightarrow{L_{i 2}}=\left(l_{i_{l-1}+1,2}, l_{i_{l-1}+2,2}, \ldots, l_{i_{l}, 2}\right), \\
\vdots \\
\overrightarrow{L_{i Q}}=\left(l_{i_{l-1}+1, Q}, l_{i_{l-1}+2, Q}, \ldots, l_{i_{l}, Q}\right),
\end{array}\right.
$$

Then, QOC used $L_{M}\left(Q^{K}\right)$ existing in $H_{1}, \ldots, H_{K}$ to establish $M$ solution (that is, the Merge layer).

Note that if $D$ is much smaller than $K$, then the first column of $D$ of $L_{M}\left(Q^{K}\right)$ can be used directly to design QOC. For example, when adopting $L_{9}\left(3^{4}\right)$, the nine products produced by QOC are nine quantized points.

According to the characteristics of the cuckoo algorithm, the update formula of the cuckoo algorithm with orthogonal crossover operator can be written as

$$
X_{j, i}^{t+1 \text { (updated) }}=(1-\omega) \times x_{\text {best }}^{t}+\omega \times x_{j, i}^{t+1},
$$

where $\omega$ is any number between 0 and 1 .

After calculating the new population using formula (9), use formula (11) to modify the population. Then, the optimal solution is searched from the revised population, and the new Lévy flight operator is calculated from the set number of iterations using formula (12). This completes the calculation of the improved cuckoo algorithm.

Figure 2 shows the flowchart of the improved cuckoo algorithm.

The flowchart of the support vector machine optimized by the modified cuckoo algorithm is shown in Figure 2. The procedures are summarized as follows:

(1) Collect samples in a training test and preconditioning the training set samples to obtain SVM learning samples.

(2) Determine the value range of SVM parameter C, $\sigma$, etc. Based on experience and the nature of the problem, initialize the parameters of the geopolymer concrete strength prediction problem, and use formula (9) to generate the initial population of control variables.

(3) Update the data of the new population, estimate the objective function, and use it as the local optimal solution.

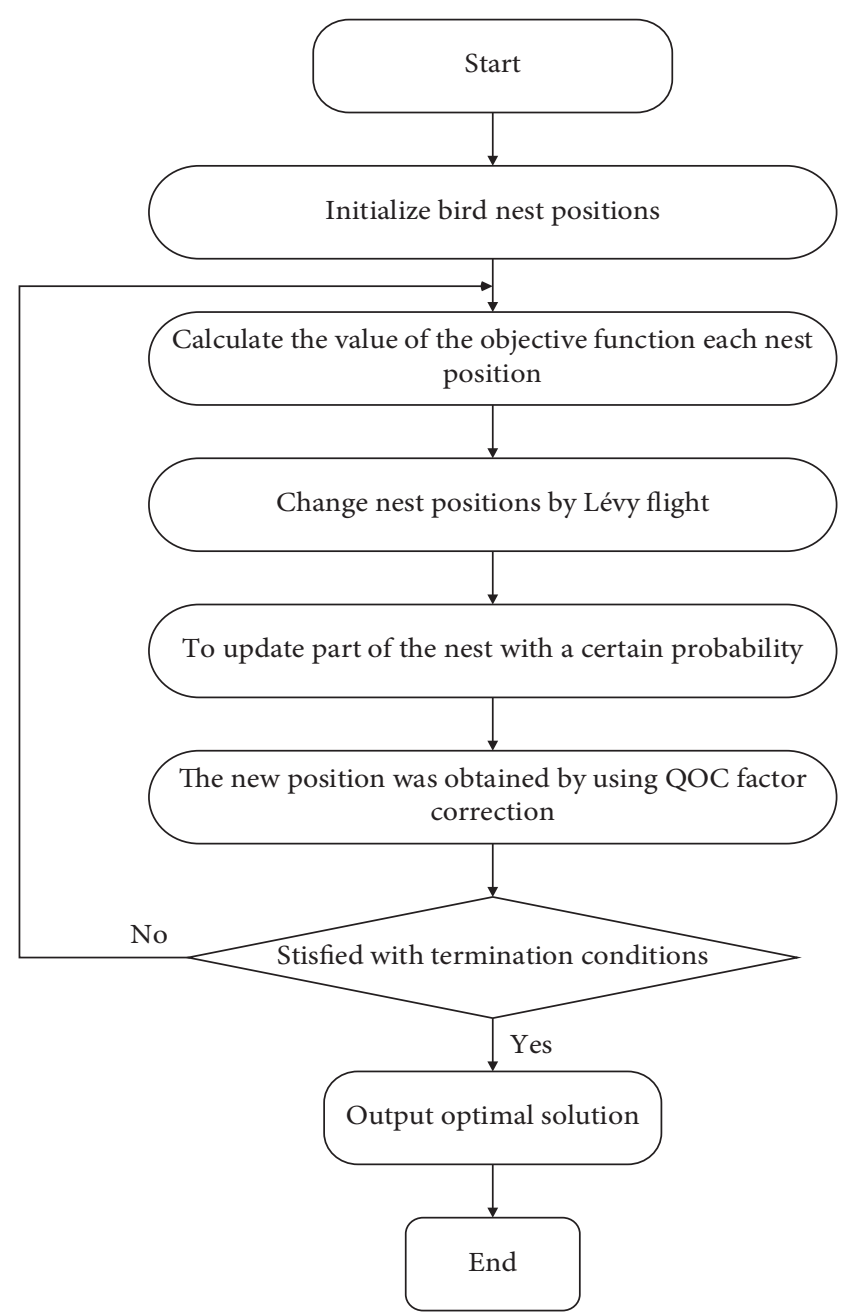

FIgURE 2: Flowchart of modified cuckoo algorithm.

(4) Calculate the Lévy flight operator using formula (9) and update the population using formula (12).

(5) Use formulas (15) and (16) to calculate the crossover operator, and then use formula (17) to calculate the revised new population.

(6) Repeat steps (3)-(5) for each iteration step to obtain the global optimal solution.

(7) When the result meets the convergence criterion, the optimal solution and control variables are output.

(8) Use formula (2) to calculate the parameters in the optimized kernel function and calculate the kernel function.

(9) The support vector machine model is optimized and calculated using the obtained kernel function to obtain each support vector and the prediction result.

\section{Prediction of Compressive Strength of Coal Gangue-Based Geopolymer Concrete}

In coal gangue based geopolymer concrete, the main raw material for preparing coal gangue is mainly composed of $\mathrm{SiO}_{2}, \mathrm{Al}_{2} \mathrm{O}_{3}, \mathrm{Fe}_{2} \mathrm{O}_{3}, \mathrm{Na}_{2} \mathrm{O}, \mathrm{K}_{2} \mathrm{O}$, and $\mathrm{CaO}$. Among them, 
$90 \%$ is contributed by $\mathrm{SiO}_{2}, \mathrm{Al}_{2} \mathrm{O}_{3}, \mathrm{CaO}$, and $\mathrm{Fe}_{2} \mathrm{O}_{3}$, and other oxides are relatively low. Studies have shown that these oxides have a great influence on the compressive strength of geopolymer concrete. However, the current studies on the compressive strength of oxides in raw materials and geopolymer concrete are mostly qualitative conclusions. In this section, based on the proposed prediction algorithm, the compressive strength of oxides in raw materials and coal gangue based geopolymer concrete is established in mathematical model, to study the basic rules of different oxides on the compressive strength of coal gangue based geopolymer concrete, give quantitative results, and provide a reliable and useful reference for the practical application of coal gangue based geopolymer concrete.

3.1. Data Training of Prediction Model. In this section, the existing experimental data will be used to train the compressive strength prediction model proposed in Chapter 4: the content of each oxide in the raw materials was taken as the input parameter of the prediction model, and the compressive strength of coal gangue based geopolymer concrete was taken as the output parameter and the results of the traditional cuckoo algorithm were compared with the prediction results of the improved cuckoo algorithm proposed in this paper. Calculation tool is MATLAB 7.0, processor Pentium $3.0 \mathrm{GHz}$, memory $8.0 \mathrm{~GB}$.

The range of values used for each oxide in the training data is shown in Table 4.

In this paper, 56 groups of data of fly ash-based geopolymer concrete in literature [14-22] were collected, of which 50 groups of compressive strength data are used as training data to train the support vector machine system, and the remaining 6 groups of data are used as a comparison of prediction results. Table 5 shows some training data. Tables 6 and 7 give the comparison of $7 \mathrm{~d}$ and $28 \mathrm{~d}$ compression strength prediction results of geopolymer concrete with different oxide content.

It can be seen from Tables 6 and 7 that the compressive strength of geopolymer concrete predicted by the prediction model proposed in this paper when the oxide content of $7 \mathrm{~d}$ and $28 \mathrm{~d}$ is different is close to the measured value, and the improved cuckoo algorithm results are similar to traditional cuckoo. The results of the bird algorithm are also very close, indicating the correctness of the prediction model proposed in this paper and the accuracy of the proposed improved cuckoo algorithm.

To explain the accuracy and superiority of the improved cuckoo algorithm proposed in this paper, the comparison between the calculation results of the traditional cuckoo algorithm and the improved cuckoo algorithm and the measured value includes the relative error and the root means square error. The relative error is the evaluation The prediction model tests each test sample, and the root means square error is the prediction model's test of the overall effect. The calculation formulas are as follows:
TABLE 4: Value range of different oxide content in coal gangue for training data.

\begin{tabular}{lcc}
\hline The name of oxide & Minimum (\%) & Maximum (\%) \\
\hline $\mathrm{SiO}_{2}$ & 40 & 60 \\
$\mathrm{Al}_{2} \mathrm{O}_{3}$ & 20 & 35 \\
$\mathrm{Fe}_{2} \mathrm{O}_{3}$ & 0 & 20 \\
$\mathrm{CaO}$ & 0 & 15 \\
\hline
\end{tabular}

$$
\begin{aligned}
\operatorname{Error}(n) & =\frac{\mid x(n, \text { true })-x(n, \text { pre }) \mid}{\mid x(n, \text { true }) \mid} \\
\text { MSE } & =\operatorname{Sqrt}\left(\frac{1}{N} \sum_{n=1}^{N} x((n, \text { true })-x(n, \text { pre }))^{2}\right) .
\end{aligned}
$$

Among them, $x$ ( $n$, true) and $x(n$,pre) are the measured value and predicted value of the nth test sample, respectively, implemented in Matlab 2010.

The relative errors predicted by using the traditional cuckoo algorithm and improved cuckoo algorithm are shown in Tables 8 and 9.

It can be seen from Tables 8 and 9 that the relative error of the compressive strength predicted by the improved gravitational search algorithm is much smaller than the predicted by the traditional gravitational search algorithm, whether it is $7 \mathrm{~d}$ or $28 \mathrm{~d}$. The average relative error of $7 \mathrm{~d}$ compressive strength predicted by the traditional gravitational search algorithm is $9.68 \%$, and the average relative error of $7 \mathrm{~d}$ compressive strength predicted by the improved gravitational search algorithm is $4.02 \%$, which is $58.47 \%$ higher than the traditional gravitational search algorithm. The relative error of the compressive strength predicted by the improved gravitational search algorithm is much smaller than that predicted by the traditional gravitational search algorithm. The average relative error of $28 \mathrm{~d}$ compressive strength predicted by the traditional gravitational search algorithm is $9.03 \%$, and the average relative error of $28 \mathrm{~d}$ compressive strength predicted by the improved gravitational search algorithm is 3.69\%, which is $59.14 \%$ higher than the traditional gravitational search algorithm. It can be seen that the prediction accuracy of the improved gravitational search algorithm is greatly improved.

To further illustrate the computational efficiency of the improved gravitational search algorithm, the calculation convergence of the traditional gravitational search algorithm is compared with that of the traditional gravitational search algorithm. Table 10 shows the comparison of the calculation residuals of the two calculation methods at the same time step in the process of seeking the optimal solution.

It can be seen that when using the same iteration step, the calculation residual of the improved gravitational search algorithm is smaller than the traditional gravitational search algorithm, and with the increase of iteration steps, the residual error of the improved gravitational search algorithm decreases faster than that of the traditional gravitational search algorithm. It indicates that the improved gravitational search algorithm accelerates the calculation convergence rate, and the calculation efficiency is higher than that of the traditional gravitational search algorithm. 
Table 5: Training data.

\begin{tabular}{|c|c|c|c|c|}
\hline \multirow{2}{*}{ Training data serial numbers } & \multirow{2}{*}{\multicolumn{2}{|c|}{ Oxide content (\%) }} & \multicolumn{2}{|c|}{ Compressive strength $(\mathrm{MPa})$} \\
\hline & & & $7 \mathrm{~d}$ & $28 \mathrm{~d}$ \\
\hline \multirow{4}{*}{1} & $\mathrm{SiO}_{2}$ & 48.21 & \multirow{4}{*}{11.2} & \multirow{4}{*}{66.1} \\
\hline & $\mathrm{Al}_{2} \mathrm{O}_{3}$ & 25.01 & & \\
\hline & $\mathrm{Fe}_{2} \mathrm{O}_{3}$ & 1.3 & & \\
\hline & $\mathrm{CaO}$ & 15.2 & & \\
\hline \multirow{4}{*}{2} & $\mathrm{SiO}_{2}$ & 51.11 & \multirow{4}{*}{38} & \multirow{4}{*}{48} \\
\hline & $\mathrm{Al}_{2} \mathrm{O}_{3}$ & 25.56 & & \\
\hline & $\mathrm{Fe}_{2} \mathrm{O}_{3}$ & 12.48 & & \\
\hline & $\mathrm{CaO}$ & 4.3 & & \\
\hline \multirow{4}{*}{3} & $\mathrm{SiO}_{2}$ & 60.02 & \multirow{4}{*}{25} & \multirow{4}{*}{37} \\
\hline & $\mathrm{Al}_{2} \mathrm{O}_{3}$ & 24.61 & & \\
\hline & $\mathrm{Fe}_{2} \mathrm{O}_{3}$ & 8.56 & & \\
\hline & $\mathrm{CaO}$ & 0.15 & & \\
\hline \multirow{4}{*}{4} & $\mathrm{SiO}_{2}$ & 49.37 & \multirow{4}{*}{9.7} & \multirow{4}{*}{26.7} \\
\hline & $\mathrm{Al}_{2} \mathrm{O}_{3}$ & 29.23 & & \\
\hline & $\mathrm{Fe}_{2} \mathrm{O}_{3}$ & 2.71 & & \\
\hline & $\mathrm{CaO}$ & 6.63 & & \\
\hline \multirow{4}{*}{5} & $\mathrm{SiO}_{2}$ & 56.01 & \multirow{4}{*}{43.26} & \multirow{4}{*}{48.2} \\
\hline & $\mathrm{Al}_{2} \mathrm{O}_{3}$ & 29.8 & & \\
\hline & $\mathrm{Fe}_{2} \mathrm{O}_{3}$ & 3.58 & & \\
\hline & $\mathrm{CaO}$ & 2.36 & & \\
\hline \multirow{4}{*}{6} & $\mathrm{SiO}_{2}$ & 65.77 & \multirow{4}{*}{16} & \multirow{4}{*}{18} \\
\hline & $\mathrm{Al}_{2} \mathrm{O}_{3}$ & 26.72 & & \\
\hline & $\mathrm{Fe}_{2} \mathrm{O}_{3}$ & 1.32 & & \\
\hline & $\mathrm{CaO}$ & 0.05 & & \\
\hline \multirow{4}{*}{7} & $\mathrm{SiO}_{2}$ & 63.18 & \multirow{4}{*}{17} & \multirow{4}{*}{15} \\
\hline & $\mathrm{Al}_{2} \mathrm{O}_{3}$ & 25.22 & & \\
\hline & $\mathrm{Fe}_{2} \mathrm{O}_{3}$ & 3.36 & & \\
\hline & $\mathrm{CaO}$ & 0.07 & & \\
\hline \multirow{4}{*}{8} & $\mathrm{SiO}_{2}$ & 73.05 & \multirow{4}{*}{7} & \\
\hline & $\mathrm{Al}_{2} \mathrm{O}_{3}$ & 23.22 & & \\
\hline & $\mathrm{Fe}_{2} \mathrm{O}_{3}$ & 0.89 & & 21 \\
\hline & $\mathrm{CaO}$ & 0.07 & & \\
\hline & $\mathrm{SiO}_{2}$ & 80.43 & & \\
\hline 9 & $\mathrm{Al}_{2} \mathrm{O}_{3}$ & 14 & 7 & 20 \\
\hline 9 & $\mathrm{Fe}_{2} \mathrm{O}_{3}$ & 3.57 & 7 & 20 \\
\hline & $\mathrm{CaO}$ & 0.04 & & \\
\hline & $\mathrm{SiO}_{2}$ & 36.02 & & \\
\hline & $\mathrm{Al}_{2} \mathrm{O}_{3}$ & 20.58 & & 34 \\
\hline 10 & $\mathrm{Fe}_{2} \mathrm{O}_{3}$ & 15.91 & 17 & 34 \\
\hline & $\mathrm{CaO}$ & 18.75 & & \\
\hline
\end{tabular}

3.2. The Influence Laws of Oxide Contents on Coal Gangue Based on Geopolymer Concrete. In this section, based on the above-trained prediction model, the mapping relationship between the compressive strength of coal gangue based on geopolymer concrete and the oxide content in the raw materials is established, and the compressive strength of coal gangue based on geopolymer concrete is predicted. According to the prediction results, the variation of compressive strength with the oxide content in the raw materials was studied.

According to the characteristics of each raw material of coal gangue based on geopolymer concrete configured in this paper, the common range of the main common oxides or oxide combination content obtained by calculation is shown in Table 11.
According to the improved gravitational search algorithm optimization method proposed above, the compressive strength of $7 \mathrm{~d}$ and $28 \mathrm{~d}$ of coal gangue based on geopolymer concrete in the range of common oxide content was predicted, and the compressive strengths of coal gangue based on geopolymer with single oxide content and common oxide mixture are given, respectively. Analysis of the influence of single oxide content and different oxide combinations on coal gangue based on geopolymer concrete provides the basis for preparing highstrength coal gangue based geopolymer concrete.

Figures 3 and 4 show the variation of $7 \mathrm{~d}$ and $28 \mathrm{~d}$ compressive strength of coal gangue based on geopolymer concrete with single oxide content, respectively, and the prediction results of the improved gravitational search algorithm and the traditional gravitational search algorithm are compared. 
TABLE 6: Comparison of 7d compressive strength for different oxide proportions.

\begin{tabular}{|c|c|c|c|c|c|}
\hline $\begin{array}{l}\text { Serial } \\
\text { number }\end{array}$ & $\begin{array}{r}\mathrm{Oxi} \\
\text { conter }\end{array}$ & $\begin{array}{l}\text { ide } \\
\text { nt(\%) }\end{array}$ & $\begin{array}{l}\text { Measured compressive strength value } \\
(\mathrm{MPa})\end{array}$ & $\begin{array}{l}\text { Traditional CSA predicted value } \\
(\mathrm{MPa})\end{array}$ & $\begin{array}{l}\text { Improved CSA predicted value } \\
(\mathrm{MPa})\end{array}$ \\
\hline 1 & $\begin{array}{c}\mathrm{SiO}_{2} \\
\mathrm{Al}_{2} \mathrm{O}_{3} \\
\mathrm{Fe}_{2} \mathrm{O}_{3} \\
\mathrm{CaO} \\
\end{array}$ & $\begin{array}{c}80.43 \\
14 \\
3.57 \\
0.04 \\
\end{array}$ & 7 & 6.33 & 6.72 \\
\hline 2 & $\begin{array}{c}\mathrm{SiO}_{2} \\
\mathrm{Al}_{2} \mathrm{O}_{3} \\
\mathrm{Fe}_{2} \mathrm{O}_{3} \\
\mathrm{CaO} \\
\end{array}$ & $\begin{array}{l}36.02 \\
20.58 \\
15.91 \\
18.75 \\
\end{array}$ & 17 & 18.78 & 16.10 \\
\hline 3 & $\begin{array}{c}\mathrm{SiO}_{2} \\
\mathrm{Al}_{2} \mathrm{O}_{3} \\
\mathrm{Fe}_{2} \mathrm{O}_{3} \\
\mathrm{CaO}\end{array}$ & $\begin{array}{c}43.7 \\
21 \\
22.5 \\
4.85\end{array}$ & 52 & 57.30 & 54.00 \\
\hline 4 & $\begin{array}{c}\mathrm{SiO}_{2} \\
\mathrm{Al}_{2} \mathrm{O}_{3} \\
\mathrm{Fe}_{2} \mathrm{O}_{3} \\
\mathrm{CaO}\end{array}$ & $\begin{array}{c}48.21 \\
25.01 \\
1.3 \\
15.2 \\
\end{array}$ & 11.2 & 9.92 & 10.52 \\
\hline 5 & $\begin{array}{c}\mathrm{SiO}_{2} \\
\mathrm{Al}_{2} \mathrm{O}_{3} \\
\mathrm{Fe}_{2} \mathrm{O}_{3} \\
\mathrm{CaO}\end{array}$ & $\begin{array}{c}56.01 \\
29.8 \\
3.58 \\
2.36\end{array}$ & 43.26 & 39.56 & 44.79 \\
\hline 6 & $\begin{array}{c}\mathrm{SiO}_{2} \\
\mathrm{Al}_{2} \mathrm{O}_{3} \\
\mathrm{Fe}_{2} \mathrm{O}_{3} \\
\mathrm{CaO}\end{array}$ & $\begin{array}{c}50.5 \\
26.57 \\
13.77 \\
2.13\end{array}$ & 66 & 60.44 & 68.85 \\
\hline
\end{tabular}

TABle 7: Comparison of $28 \mathrm{~d}$ compressive strength for different oxide proportion.

\begin{tabular}{|c|c|c|c|c|c|}
\hline $\begin{array}{l}\text { Serial } \\
\text { number }\end{array}$ & $\begin{array}{r}\text { Or } \\
\text { conte }\end{array}$ & $\begin{array}{l}\text { ide } \\
\text { it }(\%)\end{array}$ & $\begin{array}{l}\text { Measured compressive strength value } \\
(\mathrm{MPa})\end{array}$ & $\begin{array}{l}\text { Traditional CSA predicted value } \\
\qquad(\mathrm{MPa})\end{array}$ & $\begin{array}{l}\text { Improved CSA predicted value } \\
(\mathrm{MPa})\end{array}$ \\
\hline 1 & $\begin{array}{c}\mathrm{SiO}_{2} \\
\mathrm{Al}_{2} \mathrm{O}_{3} \\
\mathrm{Fe}_{2} \mathrm{O}_{3} \\
\mathrm{CaO} \\
\end{array}$ & $\begin{array}{c}80.43 \\
14 \\
3.57 \\
0.04 \\
\end{array}$ & 20 & 22.02 & 19.51 \\
\hline 2 & $\begin{array}{c}\mathrm{SiO}_{2} \\
\mathrm{Al}_{2} \mathrm{O}_{3} \\
\mathrm{Fe}_{2} \mathrm{O}_{3} \\
\mathrm{CaO}\end{array}$ & $\begin{array}{l}36.02 \\
20.58 \\
15.91 \\
18.75 \\
\end{array}$ & 34 & 30.24 & 35.96 \\
\hline 3 & $\begin{array}{c}\mathrm{SiO}_{2} \\
\mathrm{Al}_{2} \mathrm{O}_{3} \\
\mathrm{Fe}_{2} \mathrm{O}_{3} \\
\mathrm{CaO}\end{array}$ & $\begin{array}{c}43.7 \\
21 \\
22.5 \\
4.85 \\
\end{array}$ & 65 & 59.30 & 61.89 \\
\hline 4 & $\begin{array}{c}\mathrm{SiO}_{2} \\
\mathrm{Al}_{2} \mathrm{O}_{3} \\
\mathrm{Fe}_{2} \mathrm{O}_{3} \\
\mathrm{CaO}\end{array}$ & $\begin{array}{c}48.21 \\
25.01 \\
1.3 \\
15.2 \\
\end{array}$ & 66.1 & 61.03 & 64.57 \\
\hline 5 & $\begin{array}{c}\mathrm{SiO}_{2} \\
\mathrm{Al}_{2} \mathrm{O}_{3} \\
\mathrm{Fe}_{2} \mathrm{O}_{3} \\
\mathrm{CaO}\end{array}$ & $\begin{array}{c}56.01 \\
29.8 \\
3.58 \\
2.36\end{array}$ & 48.2 & 44.58 & 46.50 \\
\hline 6 & $\begin{array}{c}\mathrm{SiO}_{2} \\
\mathrm{Al}_{2} \mathrm{O}_{3} \\
\mathrm{Fe}_{2} \mathrm{O}_{3} \\
\mathrm{CaO}\end{array}$ & $\begin{array}{c}50.5 \\
26.57 \\
13.77 \\
2.13\end{array}$ & 69 & 75.23 & 66.68 \\
\hline
\end{tabular}

It can be seen from the analysis of Figures 3-4 that the prediction of the $7 \mathrm{~d}$ and $28 \mathrm{~d}$ compressive strength of coal gangue based on geopolymer concrete using the improved gravitational search algorithm is consistent with the trend of the results obtained by the traditional gravitational search algorithm. The correctness and effectiveness of the 
TABLE 8: Comparison of $7 \mathrm{~d}$ compressive strength relative error for different oxide proportions.

\begin{tabular}{|c|c|c|c|c|c|}
\hline $\begin{array}{l}\text { Serial } \\
\text { number }\end{array}$ & $\begin{array}{r}\mathrm{Ox} \\
\text { conte }\end{array}$ & $\begin{array}{l}\text { ide } \\
\text { at }(\%)\end{array}$ & $\begin{array}{c}\text { Measured compressive strength } \\
\text { value }(\mathrm{MPa})\end{array}$ & $\begin{array}{c}\text { Relative error of traditional CSA } \\
\text { prediction }(\%)\end{array}$ & $\begin{array}{c}\text { Improve the relative error of CSA } \\
\text { prediction }(\%)\end{array}$ \\
\hline 1 & $\begin{array}{c}\mathrm{SiO}_{2} \\
\mathrm{Al}_{2} \mathrm{O}_{3} \\
\mathrm{Fe}_{2} \mathrm{O}_{3} \\
\mathrm{CaO} \\
\end{array}$ & $\begin{array}{c}80.43 \\
14 \\
3.57 \\
0.04 \\
\end{array}$ & 7 & 9.01 & 4.03 \\
\hline 2 & $\begin{array}{c}\mathrm{SiO}_{2} \\
\mathrm{Al}_{2} \mathrm{O}_{3} \\
\mathrm{Fe}_{2} \mathrm{O}_{3} \\
\mathrm{CaO}\end{array}$ & $\begin{array}{l}36.02 \\
20.58 \\
15.91 \\
18.75 \\
\end{array}$ & 17 & 10.47 & 5.32 \\
\hline 3 & $\begin{array}{c}\mathrm{SiO}_{2} \\
\mathrm{Al}_{2} \mathrm{O}_{3} \\
\mathrm{Fe}_{2} \mathrm{O}_{3} \\
\mathrm{CaO}\end{array}$ & $\begin{array}{c}43.7 \\
21 \\
22.5 \\
4.85\end{array}$ & 52 & 10.2 & 3.86 \\
\hline 4 & $\begin{array}{c}\mathrm{SiO}_{2} \\
\mathrm{Al}_{2} \mathrm{O}_{3} \\
\mathrm{Fe}_{2} \mathrm{O}_{3} \\
\mathrm{CaO}\end{array}$ & $\begin{array}{c}48.21 \\
25.01 \\
1.3 \\
15.2 \\
\end{array}$ & 11.2 & 11.4 & 6.06 \\
\hline 5 & $\begin{array}{c}\mathrm{SiO}_{2} \\
\mathrm{Al}_{2} \mathrm{O}_{3} \\
\mathrm{Fe}_{2} \mathrm{O}_{3} \\
\mathrm{CaO}\end{array}$ & $\begin{array}{c}56.01 \\
29.8 \\
3.58 \\
2.36\end{array}$ & 43.26 & 8.55 & 3.54 \\
\hline 6 & $\begin{array}{c}\mathrm{SiO}_{2} \\
\mathrm{Al}_{2} \mathrm{O}_{3} \\
\mathrm{Fe}_{2} \mathrm{O}_{3} \\
\mathrm{CaO}\end{array}$ & $\begin{array}{c}50.5 \\
26.57 \\
13.77 \\
2.13\end{array}$ & 66 & 8.42 & 4.32 \\
\hline
\end{tabular}

TABle 9: Comparison of 28d predictive compressive strength for different oxide proportions.

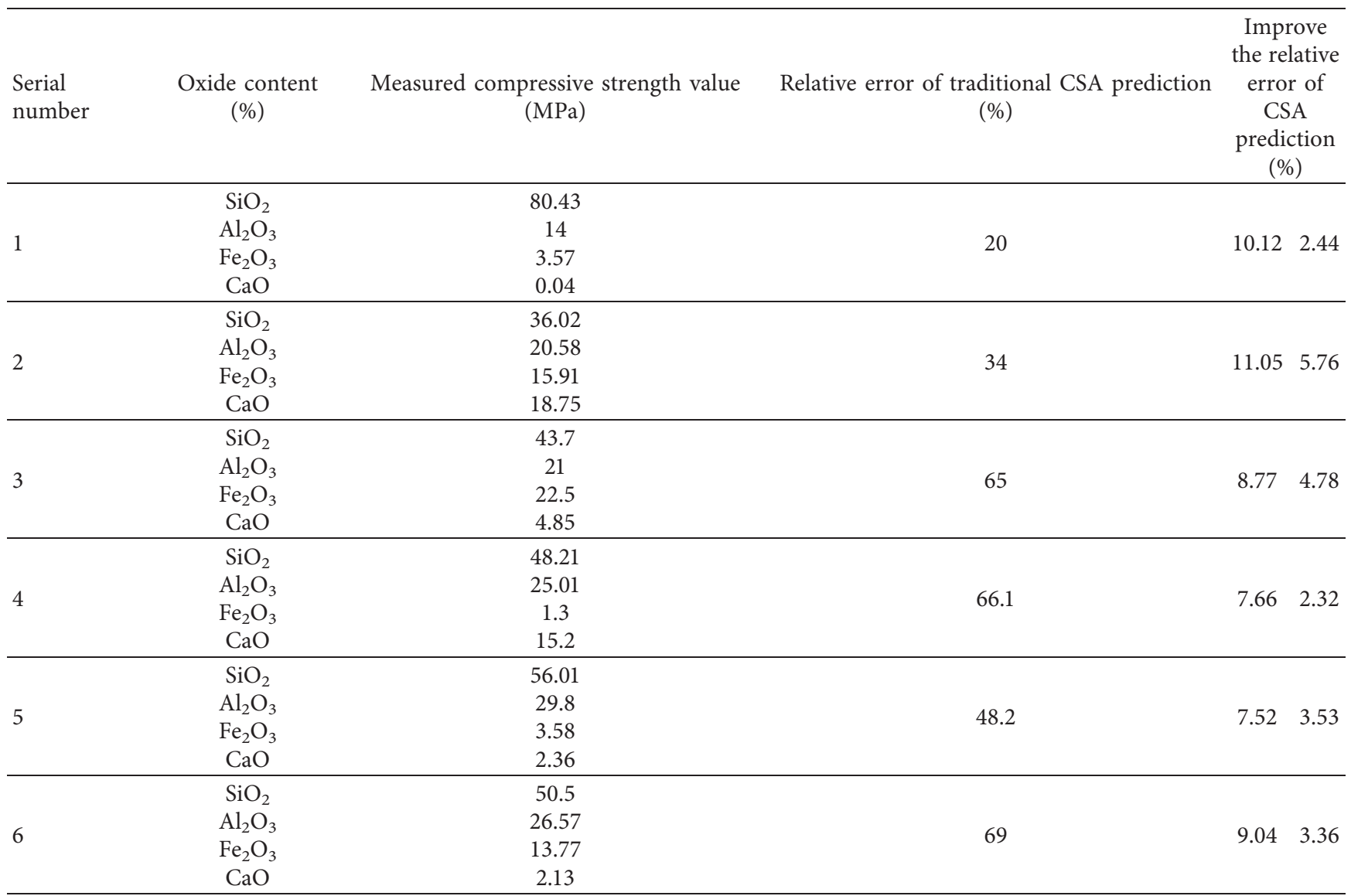


TABLE 10: Comparison of computation residuals by different methods.

\begin{tabular}{lccccc}
\hline Iterative step & 20 & 80 & 100 & 150 & 180 \\
\hline Traditional CSA & $10^{\circ}$ & $10^{-2}$ & $10^{-2}$ & $10^{-2}$ & $10^{-3}$ \\
Modified CSA & $10^{-1}$ & $10^{-3}$ & $10^{-4}$ & $10^{-4}$ & $10^{-5}$ \\
\hline
\end{tabular}

TABLE 11: Range of common oxide combination for geopolymer concrete.

\begin{tabular}{lcc}
\hline Name of oxide & Minimum (\%) & Maximum (\%) \\
\hline $\mathrm{SiO}_{2}$ & 50 & 70 \\
$\mathrm{Al}_{2} \mathrm{O}_{3}$ & 20 & 40 \\
$\mathrm{Fe}_{2} \mathrm{O}_{3}$ & 0 & 30 \\
$\mathrm{CaO}$ & 0 & 20 \\
$\mathrm{Al}_{2} \mathrm{O}_{3}+\mathrm{SiO}_{2}$ & 55 & 90 \\
$\mathrm{Fe}_{2} \mathrm{O}_{3}+\mathrm{Al}_{2} \mathrm{O}_{3}+\mathrm{SiO}_{2}$ & 65 & 95 \\
$\mathrm{CaO}+\mathrm{Fe}_{2} \mathrm{O}_{3}+\mathrm{Al}_{2} \mathrm{O}_{3}+\mathrm{SiO}_{2}$ & 80 & 97 \\
\hline
\end{tabular}

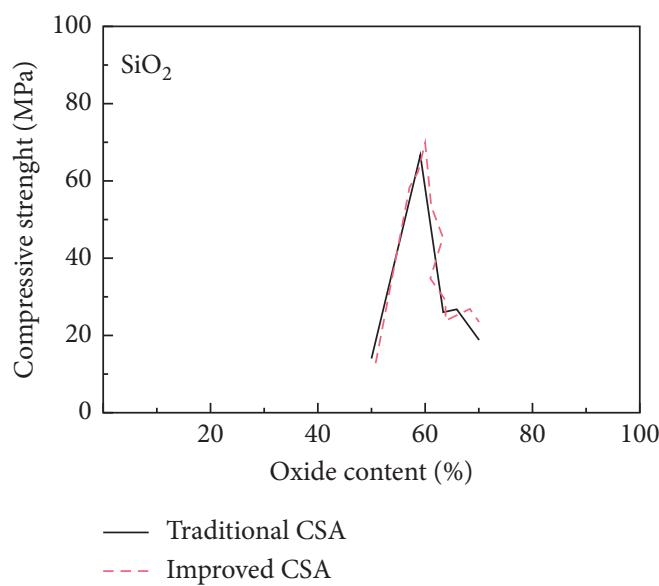

(a)

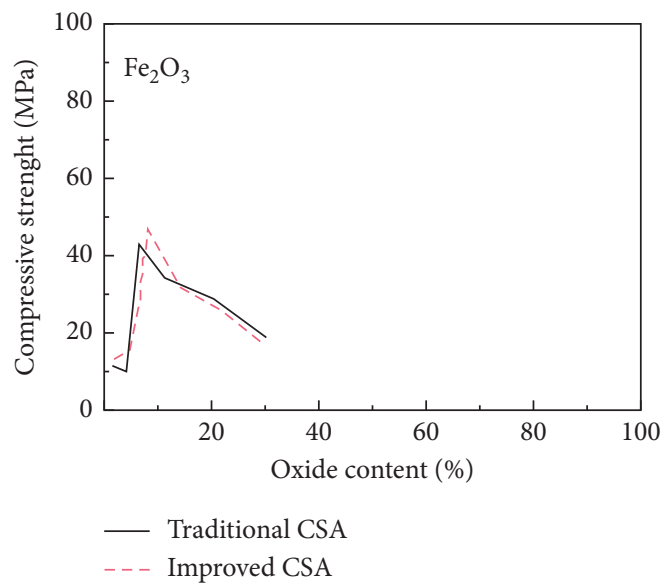

(c)

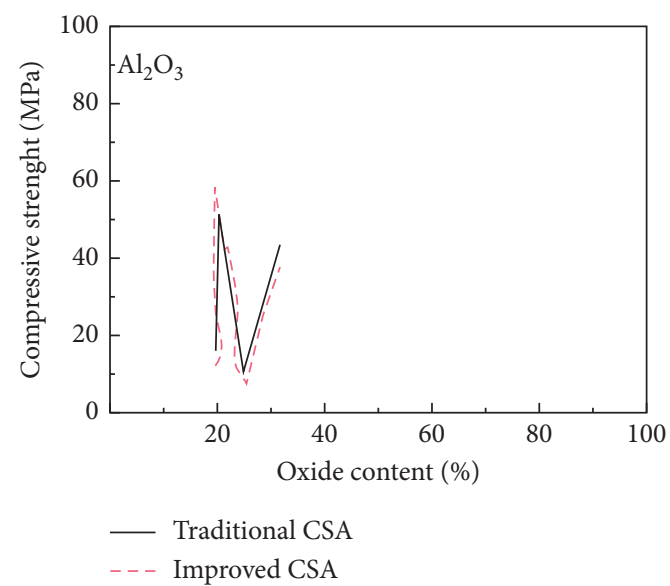

(b)

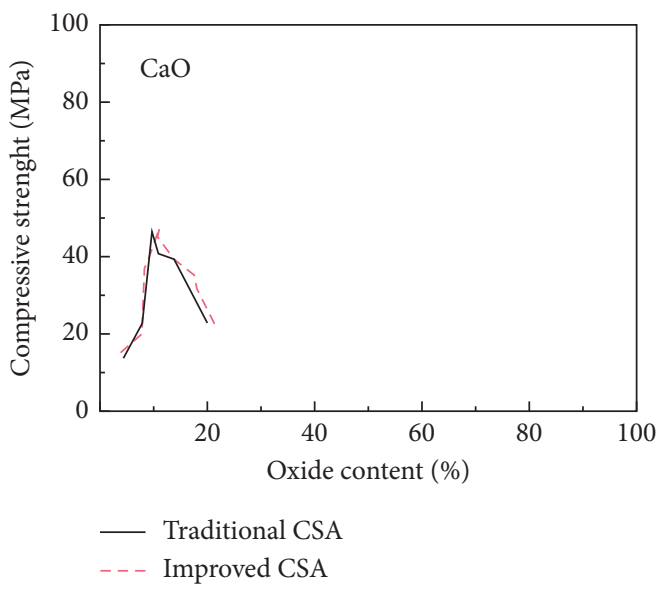

(d)

FIGURE 3: Variation of 7d compressive strength with different oxide proportion. (a) Compressive strength vs. SiO ${ }_{2}$. (b) Compressive strength vs. $\mathrm{Al}_{2} \mathrm{O}_{3}$. (c) Compressive strength vs. $\mathrm{Fe}_{2} \mathrm{O}_{3}$. (d) Compressive strength vs. $\mathrm{CaO}$.

improved gravitational search algorithm are proved once again, and the variations of compressive strength of coal gangue based on geopolymer concrete with oxide content are as follows:
(1) The 7-day compressive strength and 28-day compressive strength of concrete increased first and then decreased with the increase of $\mathrm{SiO}_{2}$ content, and the change is more dramatic. For the compressive 


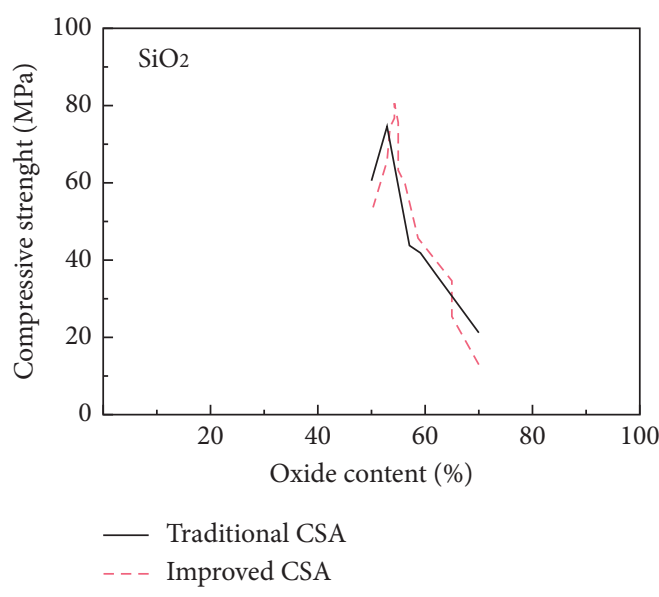

(a)

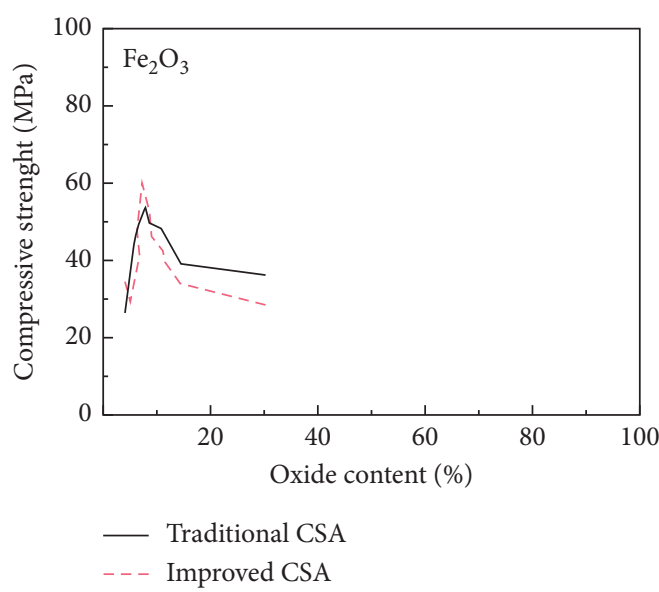

(c)

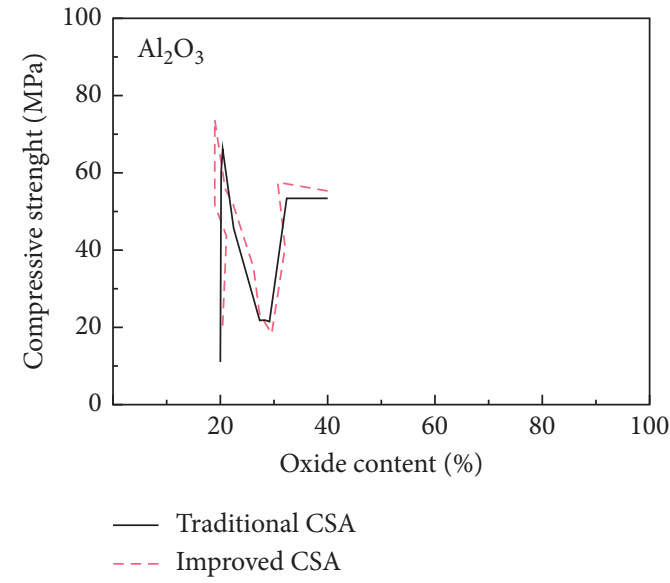

(b)

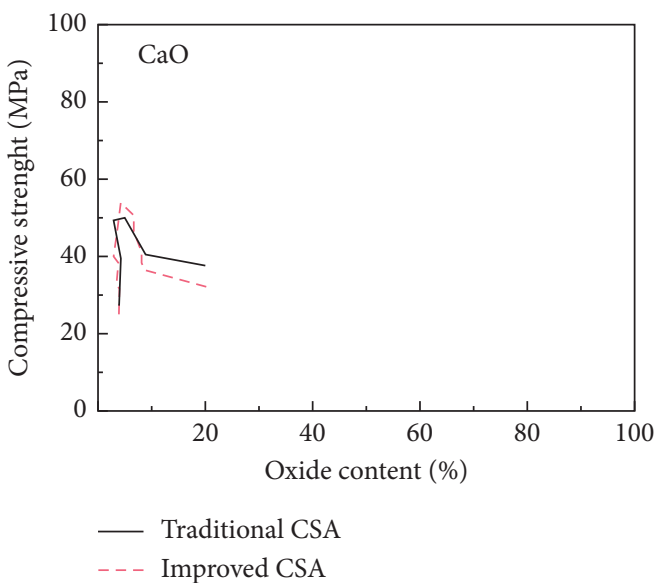

(d)

Figure 4: Variation of 28d compressive strength with different oxide proportion. (a) Compressive strength vs. $\mathrm{SiO}_{2}$. (b) Compressive strength vs. $\mathrm{Al}_{2} \mathrm{O}_{3}$. (c) Compressive strength vs. $\mathrm{Fe}_{2} \mathrm{O}_{3}$. (d) Compressive strength vs. $\mathrm{CaO}$.

strength of 7 days, when the $\mathrm{SiO}_{2}$ content is between about $50 \%$ and $60 \%$, the compressive strength increases with the increase of the $\mathrm{SiO}_{2}$ content, and the increase is larger; when the $\mathrm{SiO}_{2}$ content is between about $60 \%$ and $70 \%$, the compressive strength decreases rapidly with the increase of the $\mathrm{SiO}_{2}$ content; for the compressive strength of 28 days, when the $\mathrm{SiO}_{2}$ content is between about $50 \%$ and $55 \%$, the compressive strength increases with the increase of the $\mathrm{SiO}_{2}$ content; when the $\mathrm{SiO}_{2}$ content is between about $55 \%$ and $70 \%$, the compressive strength decreases with increasing $\mathrm{SiO}_{2}$ content; it can be seen that the optimal content of $\mathrm{SiO}_{2}$ corresponding to the compressive strength of 7 days and 28 days is $55 \%$ and $60 \%$, respectively.

(2) There is no obvious change in compressive strength of concrete with $\mathrm{Al}_{2} \mathrm{O}_{3}$ content in 7 days and 28 days, but the change of compressive strength with $\mathrm{Al}_{2} \mathrm{O}_{3}$ content is severe. For 7-day compressive strength, when the $\mathrm{Al}_{2} \mathrm{O}_{3}$ content is about $23 \%$ and $40 \%$, the compressive strength reaches the maximum; and when the $\mathrm{Al}_{2} \mathrm{O}_{3}$ content is about $28 \%$, the compressive strength is the smallest. For 28-day compressive strength, when the $\mathrm{Al}_{2} \mathrm{O}_{3}$ content is about $23 \%$, the compressive strength reaches the maximum; and when the $\mathrm{Al}_{2} \mathrm{O}_{3}$ content is about $30 \%$, the compressive strength is the smallest. It can be seen that the preferred content of $\mathrm{Al}_{2} \mathrm{O}_{3}$ is about $23 \%$.

(3) The 7-day compressive strength and 28-day compressive strength of concrete increased first and then decreased with the increase of $\mathrm{Fe}_{2} \mathrm{O}_{3}$ content. For 7day compressive strength, when the $\mathrm{Fe}_{2} \mathrm{O}_{3}$ content is between 0 and 15\%, the compressive strength increases sharply with the increase of the $\mathrm{Fe}_{2} \mathrm{O}_{3}$ content; when the $\mathrm{Fe}_{2} \mathrm{O}_{3}$ content is between $15 \%$ and $40 \%$, the compressive strength decreases sharply with the increase of $\mathrm{Fe}_{2} \mathrm{O}_{3}$ content. For 28-day compressive strength, when the $\mathrm{Fe}_{2} \mathrm{O}_{3}$ content is about $5 \%$, the compressive strength is the smallest, and when the $\mathrm{Fe}_{2} \mathrm{O}_{3}$ content is about $10 \%$, the compressive strength is the largest. It can be seen that the optimal content of $\mathrm{Fe}_{2} \mathrm{O}_{3}$ corresponding to the compressive strengths of 7 days and 28 days is $15 \%$ and $10 \%$, respectively. 
(4) The 7-day compressive strength and 28-day compressive strength of concrete increased first and then decreased with the increase of $\mathrm{CaO}$ content. For the 7-day compressive strength and 28-day compressive strength, when the $\mathrm{CaO}$ content is between 0 and $10 \%$, the compressive strength increases with increasing $\mathrm{CaO}$ content; when the $\mathrm{CaO}$ content is between $10 \%$ and $20 \%$, the compressive strength decreases with increasing $\mathrm{CaO}$ content. It can be seen that the preferred content of $\mathrm{CaO}$ is $10 \%$.

\section{Conclusions}

Based on the prediction model and algorithm proposed in the previous chapter, this chapter studies and establishes the mapping relationship between the oxides in raw materials and the compressive strength of coal gangue based geopolymer concrete. To study the basic law of different oxides on the compressive strength of coal gangue based geopolymer concrete, the main conclusions are as follows:

(1) The proposed support vector machine and the modified cuckoo algorithm are valid and accurate in predicting the compressive strength of coal ganguebased geopolymer concrete.

(2) Regardless of the compressive strength prediction results of 7 days or 28 days, the relative error of the compressive strength predicted by the improved gravitation search algorithm is much smaller than predicted by the traditional gravitation search algorithm, and the prediction accuracy of the improved gravitation search algorithm is greatly improved.

(3) The compressive strength of concrete for 7 days and 28 days increased first and then decreased with the increase of $\mathrm{SiO}_{2}$ content, and the change was more dramatic. The optimal contents of $\mathrm{SiO}_{2}$ corresponding to the compressive strength of 7 days and 28 days are $55 \%$ and $60 \%$, respectively. The optimal contents of $\mathrm{Al}_{2} \mathrm{O}_{3}$ corresponding to the compressive strength of 7 days and 28 days are about $28 \%$ and $23 \%$, respectively. The optimal contents of $\mathrm{Fe}_{2} \mathrm{O}_{3}$ corresponding to the compressive strength of 7 days and 28 days are 15 and $10 \%$, respectively. The optimal contents of $\mathrm{CaO}$ corresponding to the compressive strengths of 7 days and 28 days are $10 \%$.

\section{Data Availability}

The data used to support the findings of this study are available from the corresponding author upon request.

\section{Conflicts of Interest}

The authors declare that they have no conflicts of interest.

\section{Acknowledgments}

This study was supported by Open Foundation of Guangxi Key Laboratory of Embedded Technology and Intelligence (no. 2019-02-08), Guangxi Key Laboratory of Geomechanics and Geotechnical Engineering (GUIKENENG19-Y-21-2), National Natural Science Foundation (no. 52178468), Guangxi Key Laboratory of New Energy and Building Energy Saving Foundation (Gui Keneng 19-J-21-14), Joint Cultivation Program of National Natural Science Foundations of Guangxi (2019GXNSFAA245037), Guangxi Youth Innovative Talents research project (Guike AD19245012), and Scientific and Technology Startup Foundation of Guilin University of Technology (GUTQGJJ2019041 and GUTQDJJ2019042).

\section{References}

[1] J. Singh and S. P. Singh, "Geopolymerization of solid waste of non-ferrous metallurgy-A review," Journal of Materials Science, vol. 251, no. 1, pp. 1-12, 2019.

[2] S. K. Nath and S. Kumar, "Role of alkali concentration on reaction kinetics of fly ash geopolymerization," Journal of Non-crystalline Solids, vol. 505, no. 1, pp. 241-251, 2019.

[3] L. Wang, F. Guo, Y. Lin, H. Yang, and S. W. Tang, "Comparison between the effects of phosphorous slag and fly ash on the C-S-H structure, long-term hydration heat and volume deformation of cement-based materials," Construction and Building Materials, vol. 250, Article ID 118807, 2020.

[4] S. Tang, Y. Wang, Z. Geng et al., "Structure, fractality, mechanics and durability of calcium silicate hydrates," Fractal and Fractional, vol. 5, no. 2, 2021.

[5] Bo Fan, X. Ma, X. Lei, and X. Ma, "Real-time risk prediction of highway accidents based on support vector machine," Industrial Engineering Journal, vol. 4, no. 24, pp. 143-149, 2021.

[6] J. Li, Y. Wu, and P. Li, “TBM tunneling parameters prediction based on locally linear embedding and support vector regression," Journal of Zhejiang University, vol. 8, no. 55, pp. 1426-1435, 2021.

[7] L. Wang, S. Tang, X. Lu, M. Jin, and S. Zhou, "Investigation of microstructure of C-S-H and micro-mechanics of cement pastes under NH4NO3 dissolution by 29Si MAS NMR and microhardness," Measurement, vol. 185, Article ID 110019, 2021.

[8] K. Z. Farhan, M. A. M. Johari, and D. Ramazan, "Assessment of important parameters involved in the synthesis of geopolymer composites: a review," Construction and Building Materials, vol. 264, Article ID 120276, 2020.

[9] Y. Ling, K. Wang, X. Wang, and S. Hua, "Effects of mix design parameters on heat of geopolymerization, set time, and compressive strength of high calcium fly ash geopolymer," Construction and Building Materials, vol. 228, no. 20, pp. 937-946, 2019.

[10] D. Zhang, F. Sun, T. Liu, and Z. Xu, "Mixture ratio design optimization of coal gangue-baesd geopolymer concrete based on modified gravitational search algorithm," Journal of Advances in Civil Engineering, vol. 2021, Article ID 6620853, 2021.

[11] J.-q. Zhao, L. Wang, P. Zeng, and W. H. Fan, "An effective hybrid genetic algorithm with flexible allowance technique for constrained engineering design optimization," Expert Systems with Applications, vol. 39, no. 5, pp. 6041-6051, 2012.

[12] X.-S. Yang and S. Deb, "Multiobjective cuckoo search for design optimization," Computers \& Operations Research, vol. 40, no. 6, pp. 1616-1624, 2013.

[13] Y. Y. Wang and W. Yuping, "An orthogonal genetic algorithm with quantization for global numerical optimization," IEEE 
Transactions on Evolutionary Computation, vol. 5, no. 1, pp. 41-53, 2001.

[14] P. Duxson, J. L. Provis, G. C. Lukey, S. W. Mallicoat, W. M. Kriven, and J. S. J. D. Van, "Understanding the relationship between geopolymer composition, microstructure and mechanical properties," Colloids Surfaces A: Physicochemical and Engineering Aspects, vol. 269, no. 1-3, pp. 47-58, 2015.

[15] S. A. Bernal, J. L. Provis, and V. Rose, R.M. D. Gutierrez, Evolution of binder structure in sodium silicate-activated slag-metakaolin blends," Cement and Concrete Composites, vol. 33, no. 1, pp. 46-54, 2011.

[16] H. M. Khater, "Effect of calcium on geopolymerization of aluminosilicate wastes," American Society of Civil Engineers, vol. 24, pp. 92-101, 2021.

[17] K. Tan Neuyen, Q. D. Neuyen, T. A. Le, J. Shin, and K. Lee, Analyzing the compressive strength of green fly ash based geopolymer concrete using experiment and machine learning approaches," Construction and Building Materials, vol. 247, Article ID 118581, 2020.

[18] S. K. Das, S. M. Mustakim, A. Adesina et al., "Fresh, strength and microstructure properties of geopolymer concrete incorporating lime and silica fume as replacement of fly ash," Journal of Building Engineering, vol. 32, Article ID 101780, 2020.

[19] Z. Pan, J. G. Sanjayan, and B. V. Rangan, "Fracture properties of geopolymer paste and concrete," Magazine of Concrete Research, vol. 63, no. 10, pp. 763-771, 2011.

[20] C. Tennakoon, A. Nazari, J. G. Sanjayan, and K. S. Crentsil, "Distribution of oxides in fly ash controls strength evolution of geopolymers," Construction and Building Materials, vol. 71, pp. $72-82,2014$.

[21] B. Nematollahi and J. Sanjayan, "Effect of different superplasticizers and activator combinations on workability and strength of fly ash based geopolymer," Materials \& Design, vol. 57, pp. 667-672, 2014.

[22] Y. Park, A. Abolmaali, Y. H. K. Kim, and M. Ghahremannejad, "Compressive strength of fly ash-based geopolymer concrete with crumb rubber partially replacing sand," Construction and Building Materials, vol. 118, pp. 43-51, 2016. 